\title{
ROAD TRAFFIC ACCIDENTS: REVIEWING THE EFFICACY OF ROAD SAFETY MEASURES IN NEW SOUTH WALES, AUSTRALIA
}

\author{
PETER J. KAVALAMTHARA ${ }^{1}$, SAJAN CYRIL ${ }^{2}$, YIYANG LIU ${ }^{1} \&$ VIVIENNE SAVERIMUTTU ${ }^{1}$ \\ ${ }^{1}$ School of Business, Western Sydney University, Australia \\ ${ }^{2}$ Australian Institute of Higher Education, Australia
}

\begin{abstract}
Road traffic accidents are a major cause for concern worldwide. The World Health Organisation, in its 2018 report, estimates that approximately 1.35 million fatalities occurred on the roads in 2016. In 2009, this statistic was 1.22 million deaths per year resulting from a road accident. This steady growth has occurred despite an increasing number of countries introducing laws to promote best practice in reducing road accidents that could lead to fatalities on the road. Australia has been no exception in introducing laws targeting a reduction in accidents over the years and has been relatively successful compared to some Asian countries, for example India or China. There is a wide variation in the traffic death toll adjusted for number of vehicles or population across countries. The effectiveness of strategies adopted to manage this problem over the years also varies significantly across countries. Within Australia, New South Wales (NSW) is the most populous state and has the highest share of total vehicles in the country. Yet, the number of road traffic fatalities per 100,000 of population, in NSW, is less than the national average. This study is a review of the efficacy of road safety measures undertaken by the NSW Centre for Road Safety between 2010 and 2016 to improve road safety and reduce fatalities related to speeding. Data for the review is based on statistical reports and other studies issued by the NSW Centre for Road Safety and the Australian Bureau of Statistics. This review highlights lessons learned from the NSW experience that may be adopted by other countries in addressing this man-made disaster.
\end{abstract}

Keywords: road transport, fatalities, speeding, safety measures, lessons learned.

\section{INTRODUCTION}

In 2010, when the UN General Assembly [1] announced the "Decade of Action for Road Safety 2011-2020", the purpose was to assist countries to improve their management of this man-made hazard on various fronts and thereby save approximately five million lives. The World Health Organisation (WHO) [2], in its 2018 report, estimated that approximately 1.35 million fatalities occurred on the roads in 2016, with the number of deaths rising steadily over the years from 1.22 million in 2009. Despite this alarming statistic, the report concluded that a constant fatality rate prevailed over the timeframe, within the context of the growth in population and the rapidity of motorisation, pointing to the success of road safety measures that have been introduced over the years by many countries.

However, concern still remains as, apart from the human and social costs of road traffic accidents, the resulting trauma and injuries from an accident have lingering consequences for families, governments and associated health care systems. Further, an increasing number of countries have been introducing laws to promote best practice with the expectation of reducing motor vehicle accidents that could lead to fatalities and injuries on the road. According to the WHO [2] report, the average fatality rates differ significantly across the world between its regions and countries. Among the regions, the highest estimated average fatality rates were in Africa and South East Asia whereas Europe had the lowest rate. In low income countries, fatalities were estimated to be three times as high as in high income countries. 
Australia was no exception in introducing laws and adopting best practices targeting a reduction in accidents over the years and has been relatively successful compared to some Asian countries. Fig. 1 compares road fatalities per 100,000 of population in Australia and selected neighbouring countries [2]. Since the 1970s, Australia has been introducing initiatives to improve road safety that have steadily decreased road fatalities. Over 30 years, between 1980 and 2010, despite a 50\% growth in population and a two-fold increase in registered vehicles, road fatality rates in Australia decreased from 22.3 to 6.1 deaths per 100,000 people [3]. In 2018, the reported number of road deaths during the calendar year was estimated at 1137 [4]. The estimated annual cost of road fatalities and injuries to the Australian economy is $\$ 27$ billion based on valuing human life on the "willingness to pay" method. Using the "human capital approach", the estimate would be \$18 billion [3].

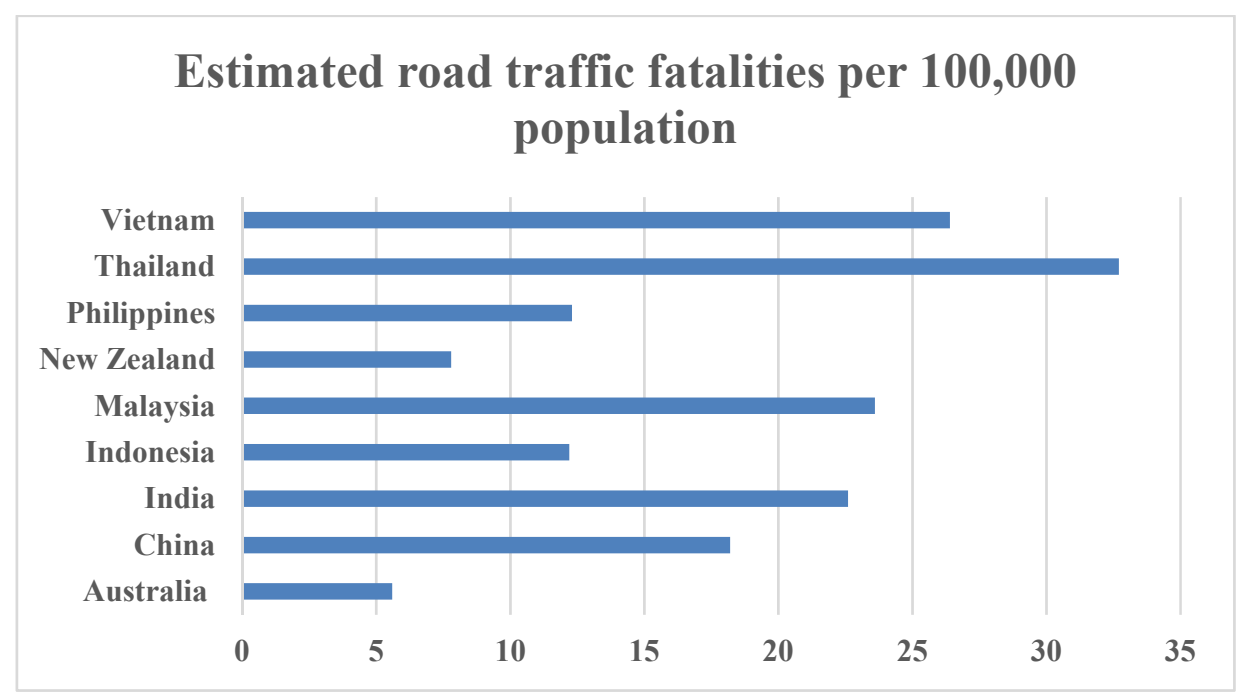

Figure 1: Comparison of road traffic fatality rates in Australia with selected Asian countries in 2016 [2].

When Australia adopted the National Road Safety Strategy 2011-2020, it was with a vision to embrace a safe system approach to reducing fatalities. This strategy is aligned with the global plan that provides direction on safe system principles. The objective is to educate road users and enforce road rules so that safety is paramount. Essentially, the adoption of this strategy is a commitment by "federal, state and territory governments", and not an implementation plan, thus requiring continued "financial, legal and administrative support" from "individual jurisdictions" [3].

Within Australia, New South Wales (NSW) is the most populous state and has the highest share of total vehicles in the country. For the year ending 30th June 2019, the number of motor vehicles in Australia was estimated at 19 million. NSW represented the highest proportion $-29 \%$ - of the national fleet as well as the highest proportion - $29 \%$ - of kilometres travelled [5]. Yet, the number of road traffic fatalities per 100,000 of population, in NSW, has consistently been less than the national average. The NSW Government plans to reduce the number of fatalities by $30 \%$ from the 2008-2009 levels by 2021 [6]. Table 1 [7] compares the road traffic fatalities per 100,000 of population of NSW with that of the national average between 2010 and 2017. 
Table 1: A comparison of road traffic fatalities per 100,000 of the population in NSW and the national average [7].

\begin{tabular}{|c|c|c|}
\hline Year & NSW & Australia \\
\hline 2010 & 5.6 & 6.1 \\
\hline 2011 & 5 & 5.7 \\
\hline 2012 & 5.1 & 5.7 \\
\hline 2013 & 4.5 & 5.1 \\
\hline 2014 & 4.1 & 5.7 \\
\hline 2015 & 4.6 & 5.1 \\
\hline 2016 & 4.9 & 5.3 \\
\hline 2017 & 4.9 & 5 \\
\hline
\end{tabular}

This study is a review of the efficacy of road safety measures undertaken by the NSW Centre for Road Safety (CSR) between 2010 and 2016 to improve road safety and reduce fatalities related to speeding. Data for the review is based on statistical reports and other studies issued by the NSW Department of Transport and the Australian Bureau of Statistics. Simple statistical analysis reveals that the three major causes of fatalities in NSW are speeding, driving under the influence of alcohol and driver fatigue. Speeding remains the major cause of death and injuries on roads in NSW despite successes in reducing fatalities. Installation of speed cameras, red light cameras and mobile speed cameras are seen as effective in reducing fatalities on roads. Application of fines and demerit points on breaching speed limits generates revenue for the State and also represses incongruent behaviour. This review highlights lessons learned from the NSW experience that may be adopted by other countries in effectively addressing this man-made disaster.

\section{ROAD FATALITIES IN NEW SOUTH WALES}

New South Wales is the most populous state in Australia with an estimated population of 7.992 million and an average growth rate of approximately $1.3 \%$ between 2011 and 2019 . This movement in population is mostly due to the job opportunities available in Sydney, the capital city of NSW and the most populated in Australia [8]. According to the vehicle registration census data NSW also has the highest number of passenger vehicles on the roads at approximately 4.3 million. However, the number of all motor vehicles including buses on NSW roads is approximately 6 million [9].

Fatalities on NSW roads have been steadily declining over the past decades. In 1970 the number of fatalities per 100,000 of population was approximately 28.9 and had declined to 4.1 per 100,000 of population by 2014 , despite the increase in the number of motor vehicles on the roads [10]. Road fatalities occur mainly due to human errors such as speeding, driving under the influence of alcohol or drugs, ignoring the use of legally enforced safety measures and succumbing to distractions such as using mobile phones while driving. Fatalities from road accidents can also occur due to unsafe roads and vehicles, inadequate post-crash care and inadequate enforcement of traffic laws [11]. Despite all the improvements, fatal crashes do still occur. An analysis of the number of fatalities that occurred on the roads in NSW between 2010 and 2017 shows that the three major reasons for fatal crashes on the roads are speeding, driving under the influence of alcohol and driver fatigue. 
Speeding proved to be by far the most dominant contributor to fatal crashes. Descriptive statistics based on data gathered over the eight-year period are given in Table 2. A one-sample t-test (Table 3) was carried out to test the hypothesis at 95\% confidence level, which confirmed that speeding was involved in at least $35 \%$ of the fatal crashes.

Table 2: Descriptive statistics: proportion of fatal crashes in NSW involving speeding, alcohol and fatigue [7].

\begin{tabular}{|l|c|c|c|c|c|c|}
\hline Variable & $\begin{array}{c}\text { Total } \\
\text { count }\end{array}$ & Mean & SE mean & Std. dev. & Minimum & Maximum \\
\hline Fatal crash (speeding) & 8 & 0.3753 & 0.0111 & 0.0313 & 0.3178 & 0.4164 \\
\hline Fatal crash (alcohol) & 8 & 0.1411 & 0.0063 & 0.01782 & 0.11781 & 0.1726 \\
\hline Fatal crash (fatigue) & 8 & 0.15925 & 0.00765 & 0.02164 & 0.12877 & 0.19178 \\
\hline
\end{tabular}

Table 3: One-sample t-test (proportion of fatal crashes involving speeding.

\begin{tabular}{|l|c|}
\hline Null hypothesis & $\mathrm{H}_{0}: \mu=0.35$ \\
\hline Alternative hypothesis & $\mathrm{H}_{1}: \mu>0.35$ \\
\hline t-value & $\mathrm{p}$-value \\
\hline 2.29 & 0.028 \\
\hline
\end{tabular}

\section{SPEEDING AS A RISK FACTOR IN FATALITIES}

The WHO, in its Global Status Report, identifies five key behavioural risk factors, such as driving over the speed limit, driving under the influence of alcohol or drugs and failing to use seat belts, motorcycle helmets or child restraints, all of which could potentially result in fatalities. Only six billion people from 123 countries have the benefit of laws enacted that promote best practice in at least one or more of these factors. Though all five risk factors are potential threats individually, the risk of speeding leading to a fatality is vastly enhanced if combined with driving under the influence of alcohol or drugs and the absence of seatbelts or child restraints. Thus speeding as a threat is in a category of its own. Only approximately three billion people from 46 countries have the protection of national laws meeting best practice in addressing speeding on roads in both urban and rural areas [1].

In 1970, Australia experienced its first sustained reduction in fatalities after the State of Victoria introduced laws requiring the use of seatbelts for both drivers and passengers, though not for children under the age of eight years. This was soon followed by the other States. Subsequently, there was a significant reduction in fatality rates resulting from an accident except for children under the age of eight years [12]. Currently laws enacted to meet best practice in 105 countries protect approximately 5.3 billion people in the world [1]. The compulsory use of restraints for children under the age of eight was not introduced until 1974, followed by continued legislation on improvements to child seats and harnesses in 1988 [13]. National child restraint laws applying to all children under the age of seven were introduced in NSW in 2010 requiring age-appropriate seating in cars [14]. A study by Brown et al. [15] found that there was improper use of child restraints among non-English speaking families of low socioeconomic status in urban Sydney after the legislation was introduced. However, it was observed that overall there was an increase in best practice use.

Random breath testing (RBT) targeting driving under the influence of alcohol was another initiative that resulted in a sustained reduction in the number of people killed or injured on 
the roads. After RBT was first introduced in NSW in 1982, the number of people that were charged in 1983 fell from 5,348 to 5,096 in 1984 emphasising the increase in community awareness as a result of the extensive publicity and the intensity of the enforcement. The savings arising from the reduced number of fatalities and changes in community behaviour were considered to be well worth the cost of the initial exercise, even though subsequently the charges laid reduced despite increased testing [16].

Speeding habits can be classified according to driver demographics. Driving above the speed limit is seen as a common trait among younger drivers than in those above 55 years of age [17]-[19]. There appears to be a difference in opinion in academic literature whether gender is a factor in speeding [17], though evidence has been presented that male drivers are more likely to crash and have higher fatality rates than females. Young male drivers were also found to be more likely to speed under the influence of alcohol. Thus according to these studies gender is crucial when it comes to speed-related crashes [17], [19], [20]. Overall, a study in NSW from 1997 to 2007 found that speed-related crashes among male drivers declined over the 10-year period [19].

Young rural drivers were also seen as more likely to be involved in speed-related crashes than young urban drivers [19], [21]. Speeding was perceived by rural drivers as inevitable and therefore acceptable. The general perception was that speeding on less dense country roads was not comparable to driving under the influence of alcohol and that it was safe to exceed the speed limit by five to ten kilometres per hour. Evidence from rural Northern Queensland also found that males were more likely to be involved in speed-related fatalities [21]. Speeding was also a risk factor among learner drivers within any age group in NSW. Distractions from outside of the vehicle posed a risk for those above 25 as well as 16-year olds. Driving at night was a risk for those aged between 20 and 25. The risk of fatalities were higher for females than males, though crash rates for males in general were higher except for those aged 25 and above [22]. Under the Graduated Licensing Scheme (GLS) introduced in 2000 , learning to drive is spread over four years to promote safer drivers. One graduates from learner to P1, then P2 before earning an unrestricted licence [23].

Other solutions to curb speeding and reduce serious injury or fatalities include speed limits in school zones with and without flashing lights. In NSW, speed is limited to $40 \mathrm{~km} / \mathrm{hr}$ with the expectation that a vehicle will travel at reduced speed prior to entering the school zone. However, more often than not, cars will slow down, whether there is a speed camera or not, only after entering the school zone. When a vehicle travelling at $50 \mathrm{~km} / \mathrm{hr}$ collides with a pedestrian the probability of a fatality doubles compared with travelling at $40 \mathrm{~km} / \mathrm{hr}$. By reducing the speed limit in NSW school zones, pedestrian casualties decreased by $45 \%$ [24], [25]. Speed limits in combination with warning signs were found to be much more effective in road work zones than speed limits alone [26]. However, excessive speeds combined with driver inattention have resulted in roadwork zone crashes [27]. One of the most effective ways of controlling speed is police presence implying a high probability of being charged [28].

\section{EFFECTIVENESS OF NSW SPEED CAMERA STRATEGY}

Vehicles travelling above the speed limit or at inappropriate levels of speed during risky conditions increase the likelihood of fatalities or at the very least serious injury. The strategy for speed enforcement in NSW is based on an integrated framework that conforms to universal best practice in improving road safety. Fixed and red-light speed cameras that are signposted and clearly marked mobile speed cameras are listed such that the public are clearly warned of their locations. The aim of the speed camera enforcement program is to change 
behaviour patterns through promoting the perception of punishment if an infringement occurs and thus reducing fatalities and injuries [29].

The program is reviewed periodically to assess the safety benefit of cameras and requires a minimum of five years of post-installation data to assess the reduction in casualty crashes, casualties and infringement rates. A camera location is included in the review only if the required data is available. Recommendations are made for each camera location based on the findings [30]. A fatality is said to have occurred if a person dies within 30 days of a crash. A casualty crash refers to death occurring immediately as a result of the crash. To measure the reduction in fatalities at camera locations, which is a part of the overall review of the program, fatalities at each location over five years prior to the installation of a camera are compared to fatalities in each current five-year analysis period [31].

\subsection{Fixed speed camera program}

The fixed speed camera program commenced in NSW in 1997. Most of the fixed speed cameras have been installed for at least for five years now. The purpose was to address problem areas (black spots) with a history of crashes by locating cameras at road lengths such that they deter speeding [30]. At the end of 2016, there were 138 cameras at 109 locations however only 94 locations were reviewed for the purpose of recommendations [29].

Using the methodology described in Section 3, the annual reductions in fatalities, as a result of the installed fixed speed cameras were calculated and reported by the CRS in their annual reviews. For the year ended 2016, the reduction in fatalities due to fixed speed cameras was $85 \%$ [29]. Descriptive statistics based on reductions in fatalities over a seven-year period (2010-2016) are reported in Table 4.

A one-sample t-test (Table 4) was carried out to test the hypothesis at $95 \%$ confidence level which confirmed fixed speed cameras contributed to a reduction in fatalities by at least $75 \%$ in locations where they were installed.

Table 4: Descriptive statistics and one sample t-test: reduction in fatalities at fixed speed camera locations.

\begin{tabular}{|c|c|c|c|c|}
\hline \multicolumn{5}{|c|}{ Descriptive statistics } \\
\hline \multicolumn{4}{|c|}{ Fixed speed camera locations } & 95\% Lower bound \\
\hline $\mathrm{N}$ & Mean & Std. dev & SE mean & for $\mu$ \\
\hline 7 & 0.86 & 0.0872 & 0.033 & 0.796 \\
\hline \multicolumn{5}{|c|}{$\mu$ : mean of reduction in fatalities } \\
\hline \multicolumn{3}{|c|}{ t-test } & & \\
\hline Null hypothesis & \multicolumn{2}{|c|}{$\mathrm{H}_{0}: \mu=0.75$} & & \\
\hline Alternative hypothesis & \multicolumn{2}{|c|}{$\mathrm{H}_{1}: \mu>0.75$} & & \\
\hline t-value & \multicolumn{2}{|c|}{$\mathrm{p}$-value } & & \\
\hline 3.34 & \multicolumn{2}{|c|}{0.008} & & \\
\hline
\end{tabular}

\subsection{Red-light speed camera program}

The red-light speed camera program was introduced in 2009. The cameras are installed at high risk intersections with signals where the driver is at risk of a right-angle crash or a pedestrian is at risk of being killed. The cameras are designed to deter both speeding and running a red-light. Intersections are high risk as fatalities can occur even at low speeds, given the unexpectedness of a car running a red light [31]. 
At the end of 2016, there were 191 cameras at 171 locations, however, only 91 locations were reviewed for the purpose of recommendations as data was not available. The five-year post-installation requirement was not met at 80 locations [29].

Using the same methodology as for fixed speed cameras, the annual reductions in fatalities resulting from the installed red-light speed cameras were calculated and reported by the CRS in their annual reviews. At least half of the red-light cameras meet the post installation requirement of a minimum of five years. For the year ended 2016, a reduction in fatalities due to red-light speed cameras was 54\% [29].

Descriptive statistics based on reductions in fatalities over a 7-year period (2010-2016) are reported in Table 5. A one-sample t-test (Table 5) was carried out to test the hypothesis at $95 \%$ confidence level which confirmed that red-light speed cameras have contributed to a reduction in fatalities by at least $40 \%$ during that period in locations where they were installed.

Table 5: Descriptive statistics and one-sample t-test: reduction in fatalities at red-light camera locations.

\begin{tabular}{|c|c|c|c|c|}
\hline \multicolumn{5}{|c|}{ Descriptive statistics } \\
\hline $\mathrm{N}$ & Mean & Std. dev & SE mean & f5\% Lower bound $\mu$ \\
\hline 7 & 0.86 & 0.0872 & 0.033 & 0.796 \\
\hline \multicolumn{5}{|c|}{$\mu:$ mean of reduction in fatalities } \\
\hline \multicolumn{4}{|c|}{$\mathrm{t}$-test } & \\
\hline Null hypothesis & $\mathrm{H}_{0}: \mu=0.75$ & \\
\hline Alternative hypothesis & \multicolumn{1}{|c|}{$\mathrm{H}_{1}: \mu>0.75$} & \\
\hline t-value & \multicolumn{2}{|c|}{$\mathrm{p}$-value } & \\
\hline 3.34 & \multicolumn{2}{|c|}{0.008} & \\
\hline
\end{tabular}

\subsection{Mobile speed camera program}

Mobile speed cameras were originally introduced in 1991 and ceased operations in 2008. In 2009 , speed-related crashes increased by $36 \%$ and the death toll increased by $20 \%$ compared to the categories in 2008. Consequently, mobile speed cameras were reintroduced 2010 . Thus they are considered highly effective in producing a sustained change in speeding behaviour as they may be located anywhere along the road network and drivers are unable to predict where or when they could be caught speeding [32]. As with the other two speed camera programs, warning signs display the speed limit as the driver approaches and the mobile speed camera vehicles are highly visible. In this program speed and crash data are collected across NSW and not at any specific mobile speed camera location [31]. Table 6 shows the total number of traffic fatalities and fatalities related only to speed [7]. The data suggests a decrease in fatalities for both categories from 2010 to 2016 in comparison with 2009. The statistical significance of the percentage decrease in total and speed-related fatalities is tested further.

Descriptive statistics are given for total road traffic fatalities in Table 7 and speed related fatalities in Table 8. One sample t-tests carried out at 95\% confidence levels confirm that the decrease in total traffic fatalities is at least $15 \%$ in comparison with total fatalities in 2009, while the decrease in speed related fatalities is at least $20 \%$ in comparison with speed related fatalities in 2009. 
Table 6: Road-traffic fatalities in NSW 2009-2016: total and speed-related.

\begin{tabular}{|c|c|c|}
\hline \multirow{2}{*}{ Year } & \multicolumn{2}{|c|}{ Number of road traffic fatalities } \\
\cline { 2 - 3 } & Total & Speed-related \\
\hline 2009 & 453 & 207 \\
\hline 2010 & 357 & 161 \\
\hline 2011 & 364 & 152 \\
\hline 2012 & 364 & 146 \\
\hline 2013 & 309 & 140 \\
\hline 2014 & 307 & 127 \\
\hline 2015 & 350 & 146 \\
\hline 2016 & 380 & 159 \\
\hline
\end{tabular}

Table 7: Descriptive statistics and one-sample t-test: A decrease in total traffic fatalities 2010-2016 in comparison with total traffic fatalities in 2009.

\begin{tabular}{|c|c|c|c|c|}
\hline \multicolumn{5}{|c|}{ Descriptive statistics } \\
\hline $\mathrm{N}$ & Mean & $\begin{array}{c}\text { Std. } \\
\text { dev }\end{array}$ & $\begin{array}{c}\text { SE } \\
\text { mean }\end{array}$ & for $\mu$ \\
\hline 7 & 0.2336 & 0.0628 & 0.0237 & 0.1875 \\
\hline \multicolumn{4}{|c|}{$\mu$ : Mean of \% decrease (total) traffic fatalities } \\
\hline \multicolumn{3}{|c|}{$\mathrm{t}$-test } \\
\cline { 1 - 2 } Nult hypothesis & $\mathrm{H}_{0}: \mu=0.15$ \\
\cline { 1 - 2 } & $\mathrm{H}_{1}: \mu>0.15$ \\
\hline t-value & $\mathrm{p}$-value \\
\hline 3.52 & 0.006 & \\
\hline
\end{tabular}

Table 8: Descriptive statistics and one-sample t-test: a decrease in speed-related fatalities 2010-2016 in comparison with speed-related fatalities in 2009.

\begin{tabular}{|c|c|c|c|c|}
\hline \multicolumn{5}{|c|}{ Descriptive statistics } \\
\hline $\mathrm{N}$ & Mean & Std. dev & SE mean & for $\mu$ \\
\hline 7 & 0.288 & 0.0576 & 0.0218 & 0.2457 \\
\hline \multicolumn{5}{|c|}{ Speed related fatalities } \\
\hline \multicolumn{3}{|c|}{ t-test of \% decrease (Speed-related) fatalities } \\
\hline Null hypothesis & \multicolumn{3}{|c|}{$\mathrm{H}_{0}: \mu=0.2$} & \\
\hline Alternative hypothesis & \multicolumn{2}{|c|}{$\mathrm{H}_{1}: \mu>0.2$} \\
\hline t-value & \multicolumn{3}{|c|}{$\mathrm{p}$-value } \\
\hline 4.04 & \multicolumn{2}{|c|}{0.003} & \\
\hline
\end{tabular}

\section{CONCLUSION, RECOMMENDATIONS AND LIMITATIONS}

Australia's record in best practice traffic law enforcement over the years has resulted in a lower road traffic fatality rate in comparison with neighbouring countries (Fig. 1). The performance of NSW, the most populous state with $29 \%$ of the national fleet (the highest proportion in comparison with other states), in lowering its traffic fatalities per 100,000 of population has been consistently better than the national average between 2010 and 2017 
(Table 1). This is clearly due to law enforcement of best practice that has been gradually introduced since the 1970s. In 1970 the road fatality rate in NSW was 28.9 per 100,000 of population and it fell to 4.1 per 100,000 of population. Since then the fatality rate has steadily risen to 4.9 per 100,000 of population in 2017. Speeding has been identified as the main reason for the increase in road fatalities. The speed camera programs are still effective and of the three programs, mobile speed cameras are the most effective. This was proven when the fatality rates rose in 2009 after the cessation of the program in 2008, and a decrease was experienced after its reintroduction.

The CRS has reported that data on fatalities related to driving under the influence of illicit substances is available only for fatal crashes and for the financial years ending 2010-2011 to 2015-2016. Data for non-fatal crashes are not available. Thus a limitation of this paper is that driving under the influence of drugs may not have been excluded from the speed related data though speeding was a factor in the fatal crash. A probable explanation for the increase in fatalities since 2014 is the increased use of illicit drugs while driving. The information available shows that the percentage of total fatalities involving a motor vehicle controller with an illicit drug was $15.7 \%$ in the 2013-2014 financial year and rose sharply to $20.6 \%$ by the 2015-2016 financial year [33].

However, based on the NSW experience up to 2014 it is still possible to make recommendations on how to manage this man-made disaster. There are many lessons to be learned from the NSW experience by developing countries where road traffic fatalities are high. Strategies that benefitted NSW include the following. The introduction of the compulsory use of seatbelts in 1971 though children under 8 were excluded until legislation was introduced in 1974. This was followed by the introduction of RBT in 1982. National child legislation on improvement to child seats and harnesses was adopted in 1988. In 1990, the Road Safety (RS) 2000 strategy was adopted. During this period fixed speed cameras and mobile speed cameras were introduced [10]. Also in 1995, the then premier of NSW committed his government to reducing deaths by 500 and serious injuries by 5,500 as part of the RS 2000 strategy [34]. The "National Walk Safely to School Day" was introduced and is now in its 20th year [35]. Consequent to all these traffic law enforcements and the steady decline in road fatalities, in 2000 the trend began to reverse [36] and in the same year the 2000 Graduated Licensing Scheme was introduced.

In 2012 the Road Safety Strategy 2012 to 2021 was adopted. This strategy emphasises a safe system approach following Scandinavian best practice. The underlying elements are safer people, safer roads, safer speeds and safer vehicles [37]. A topic for future research is the innovative road safety initiatives that are now being pursued in earnest by the CRS with full support from all levels of Government to reverse the increasing trend in fatalities that has occurred since 2014.

[1] WHO \& UN Road Safety Collaboration, Decade of Action for Road Safety 20112020. www.who.int/roadsafety/decade_of_action/en/. Accessed on: 30 Aug. 2019.

[2] WHO, Global Status Report on Road Safety. 2018. www.who.int/violence_injury_ prevention/road_safety_status/2018/en/. Accessed on: 24 Jul. 2019.

[3] Australian Transport Council, National Road Safety Strategy 2011-2020. www.roadsafety.gov.au/nrss/files/NRSS_2011_2020.pdf. Accessed on: 30 Aug. 2019.

[4] Department of Infrastructure, Transport, Cities and Regional Development, BITRE. www.bitre.gov.au/statistics/safety/. Accessed on: 30 Aug. 2019.

[5] Australian Bureau of Statistics, Survey of motor vehicle use, Australia. www.abs.gov.au/ausstats/abs@.nsf/mf/9208.0. Accessed on: 30 Aug. 2019. 
[6] NSW Government, Road Safety Plan 2021. Towards Zero. https://towardszero.nsw.gov.au/sites/default/files/2018-02/road-safety-plan.pdf. Accessed on: 30 Aug. 2019.

[7] Centre for Road Safety, Road traffic casualty crashes in New South Wales. Statistical Statements for Years ended 2010 to 2017. https://roadsafety.transport.nsw.gov.au/ downloads/crashstats2017.pdf. Accessed on: 24 Jul. 2019.

[8] Population Australia, NSW population, 2019. www.population.net.au/population-ofnew-south-wales/. Accessed on: 20 Aug. 2019.

[9] Motor Vehicle registration slowdown.www.abs.gov.au/ausstats/abs@.nsf/lookup/ 9309.0Media\%20Release131\%20Jan\%202019.

[10] Transport NSW, Centre for Road Safety. https://roadsafety.transport.nsw.gov.au/ statistics/fatalitytrends.html. Accessed on: 20 Aug. 2019.

[11] WHO, Road traffic injuries. www.who.int/news-room/fact-sheets/detail/road-trafficinjuries. Accessed on: 20 Aug. 2019.

[12] McDermott, F.T. \& Hough, D.E., Reduction in road fatalities and injuries after legislation for compulsory wearing of seat belts: experience in Victoria and the rest of Australia. British Journal of Surgery, 66(7), pp. 518-521, 1979.

[13] Department of Infrastructure, Transport, Cities and Regional Development, Vehicle occupant protection in Australia. www.infrastructure.gov.au/roads/safety/ publications/1988/pdf/Prot_Aust_1.pdf. Accessed on: 31 Aug. 2019.

[14] Child Restraint Laws in NSW, www.repcoservice.com/car-care-advice/child-car-seatlaws/child-restraint-laws-nsw. Accessed on: 31 Aug. 2019.

[15] Brown, J., Keay, L., Hunter, K., Bilston, L.E., Simpson, J.M. \& Ivers, R., Increase in best practice child car restraint use for children aged 2-5 years in low socioeconomic areas after introduction of mandatory child restraint laws. Australian and New Zealand Journal of Public Health, 37(3), pp. 272-277, 2013.

[16] TRID, The National Academies of Sciences Engineering Medicine. The impact of random breath testing in New South Wales. https://trid.trb.org/view/1194447. Accessed on: 31 Aug. 2019.

[17] Ellison, A.B. \& Greaves, S., Driver characteristics and speeding behaviour. Proceedings of the 33rd Australasian Transport Research Forum (ATRF'10), 2010.

[18] Ogle, J.H., Quantitative Assessment of Driver Speeding Behaviour using Instrumented Vehicles. Doctoral dissertation, Georgia Institute of Technology.

[19] Chen, H.Y. et al., Road crash trends for young drivers in New South Wales, Australia, from 1997 to 2007. Traffic Injury Prevention, 11(1), pp. 8-15, 2010.

[20] Wundersitz, L., Hiranandani, K. \& Baldock, M., Annual Performance Indicators of Enforced Driver Behaviours in South Australia, 2007, Centre for Automotive Safety Research, 2009.

[21] Knight, P.J., Iverson, D. \& Harris, M.F., Early driving experience and influence on risk perception in young rural people. Accident Analysis \& Prevention, 1(45), pp. 775781, 2012.

[22] Lam, L.T., Factors associated with young drivers' car crash injury: comparisons among learner, provisional, and full licensees. Accident Analysis \& Prevention, 35(6), pp. 913-920, 2003.

[23] Centre for Road Safety, Australian graduated licensing scheme. Policy framework. https://roadsafety.transport.nsw.gov.au/downloads/gls.pdf. Accessed on: 2 Sep. 2019.

[24] Ellison, A.B., Greaves, S.P. \& Daniels, R., Speeding behaviour in school zones. Proceedings of the Australasian College of Road Safety National Conference, 2011. 
[25] Peden, M. et al., World Report on Road Traffic Injury Prevention, World Health Organization, 2004.

[26] Haworth, N., Symmons, M. \& Mulvihill, C., Safety of Small Workgroups on Roadways, 2002.

[27] Garber, N.J. \& Patel, S.T., Control of vehicle speeds in temporary traffic control zones (work zones) using changeable message signs with radar. Transportation Research Record, 1995.

[28] Arnold, E.D., Use of Police in Work Zones on Highways in Virginia, Virginia Transportation Research Council, 2003.

[29] Centre for Road Safety, Speed camera programs: Annual Review 2017. https://roadsafety.transport.nsw.gov.au/downloads/2017-speed-camera-reviewappendices.pdf. Accessed on: 1 Sep. 2019.

[30] Carseldine, D., RTA: Fixed, digital speed cameras in NSW - Impacts on vehicle speeds and crashes. https://acrs.org.au/files/arsrpe/RS030027.pdf. Accessed on: 1 Sep. 2019.

[31] Centre for Road Safety, Speed camera programs: Annual Review 2015. https://roadsafety.transport.nsw.gov.au/downloads/2015-speed-camera-review.pdf. Accessed on: 1 Sep. 2019.

[32] NSW Government, Transport for NSW, NSW speed camera strategy 2012. www.rms.nsw.gov.au/roadsafety/downloads/nsw_speed_camera_strategy.pdf. Accessed on: 3 Sep. 2019.

[33] Centre for Road Safety, Drug driving trauma trends: Report. https://roadsafety.transport.nsw.gov.au/downloads/trauma-trends-drug-driving.pdf. Accessed on: 2 Sep. 2019.

[34] Pedestrian Council of Australia, Excerpt from the Foreword to STAYSAFE 47, 1998. www.walk.com.au/pedestriancouncil/Page.asp?PageID=573. Accessed on: 2 Sep. 2019.

[35] WSTSD, www.walk.com.au/WSTSD/. Accessed on: 2 Sep. 2019.

[36] Road Transport Authority, Road traffic accidents NSW, 2000. Statistical statement. https://roadsafety.transport.nsw.gov.au/downloads/accidentstats2000.pdf. Accessed on: 2 Sep. 2019.

[37] Centre for Road Safety, Towards zero a safe system approach. https://roadsafety.transport.nsw.gov.au/aboutthecentre/safe-system/index.html. Accessed on: 3 Sep. 2019. 